\title{
Language barrier, legal translation and the judicial system: an elaboration on the concepts and principles
}

\begin{abstract}
Through Legal Translation, as a professional practice of certified translators as well as experienced freelancers, the translators have to deal not only the common problems of the practice but, those who, due the difficulty of legal language, needing in-depth knowledge and understanding of the field. Different judicial systems employ different terminology and encounter issues with varying degrees of formality necessitating existence of some kind of intervention for those in need which facilitates and provides for proper communication to happen between the judicial staff and those who refer to them as speakers of a different language. The present paper elaborates on the concepts and principles of legal translation in relation to the potential barrier it might impose on the process of communication in the offices affiliated to the judiciary systems.
\end{abstract}

Keywords: legal translation, language barriers, judicial system, victims
Volume 7 Issue 6 - 2019

\author{
Mehdi Asadzadeh,' Mehran Asadzadeh² \\ 'Department of English and Translation Studies, Islamic Azad \\ University, Iran \\ 2Department of Law, Zanjan Branch, Islamic Azad University, \\ Zanjan, Iran
}

Correspondence: Mehdi Asadzadeh, Department of English and Translation Studies, Maragheh Branch, Islamic Azad University, Maragheh, Iran, Tel +989|20877409,

Email Asadzdeh.me@gmail.com

Received: November 17, 2019 | Published: December 17, 2019

\section{Introduction}

The main purpose of the language is to serve as means of linking individuals. However, interpreters and interpreters are required to deal with the specific characteristics of their field each day. Certainly, legal terminology and idiom impose the most troublesome features. This has become a big concern for all translators and interpreters who need to participate in legal systems at universal level, sometimes especially varied. The legal language based on ordinary language is semiotic and semi-autonomous. Also, the terminological density is high and most of the terms have different meanings depending on the legal field to which they belong. That's why translation of legal texts and documents requires several complex skills. It is necessary not only to have a comprehensive knowledge of general linguistics, but also to understand the original including the vocabulary and content and knowledge of parallel legal systems. Of course, the experience is also positive to translate original documents into the target language.

The decisive importance of the language of law for its application is indisputable in our society. To establish norms, rules and principles that define the relationships between people in a particular field community must be clarified. Due to the use of legal language to describe the existence, interests and property of human beings, there should be a basic expectation to eliminate uncertainty and lack of sensitivity; and to reduce confusion and misinterpretation between concise language and users. But expectations completely different from reality. Therefore, it is necessary to conduct a detailed terminological research. To guarantee proper translation and correct comprehension. To avoid making mistakes during the legal translation process, it is necessary to recognize and understand the features specific to the legal language.

However, it is not always easy to observe these features, because some may appear in others. Language types or may not be defined at first glance. ${ }^{1}$ Errors can occur at all levels: lexical, semantic, grammatical structure, stylistic features etc. we would like to propose the application of terminological analyzes useful for translation.
Translators and interpreters in their daily duties. Terminology is, among other things, a studied discipline, developing specific terms and their relationships within a specific field. One of the most important aims of terminology is to remove uncertainty from the technique through standardization of terminology to make them efficient tools.

\section{The translation of legal texts}

There are many factors that contribute to the difficulty of legal translation work, and we'll look at two of them below. One of the most difficult aspects of legal translation that linguists have to solve is the fact that legal systems in different countries can be quite different. This means that legal translators must deal not only with two different languages and cultures, but with two completely different legal systems for translation between them. To further complicate the problem, legal systems can be different within a single state with a common language. For example, common law applies as a basis for the legal system in England and Wales, but not in Scotland. Even more confusing, while common law applies to the United States, it does not fully apply to Louisiana, which has a mixed legal system!

Another factor that raises challenges for translators is the fact that legal concepts are not the same in different countries and can vary within the same country! For example, while the word "marriage" may be clear enough to translate across languages, the actual legal concept is much more complex. The laws surrounding marriage vary widely from culture to culture, and the age of marriage is not a definite concept. There is no legal minimum age for marriage in some countries (Maldives, Saudi Arabia), some are under the legal age of 9 years (parts of Lebanon), and some legal marriage age is 22 (men in China). In addition, it is common for States to have different legal ages based on sex. For example, men are legally allowed to marry at the age of 18 in Chad, Niger and Iran, whereas in these countries, girls are legally allowed to marry at the age of 15 . So for a legal translator, not just as simple as translating a marriage word, they should be aware of the differences in legal systems and legal concepts around the world! 
Obviously, legal translation is a very complex issue that can only be done by a professional legal translator. It is not enough for the translator to have knowledge of the source and target language.

Generally, 2 major challenges face the legal translators. They include:

1. Legal Language: Legal documents that often end up with language features you won't find anywhere else. For example, you've seen longer sentences than the text of this article that runs for more than one page. As another example, it is almost universal practice when writing lists in legal documents to separate items in the list with semicolons instead of commas. The purpose is to try to indicate through punctuation that all items in the list should be just as important - not something you normally think of when writing your shopping list!

As a translator, this type of construction and extraordinary agreements can pose significant challenges. If you have a 600 -word sentence that needs to be translated into a language where the structure of the sentence is necessarily different from the structure used in the source language (for example, when translating from English to German or vice versa), how an interpreter tracks all the different parts of the sentence enough to organize The end result correctly?

2. Difference in Legal and Judicial Systems of Different Countries: Another common challenge for legal translators is how to translate a unique idea into a legal system in a way that is easily understood by people within another legal system. There are concepts in some legal systems and jurisdictions that do not have a similar term or concept in others. The extent of these differences varies greatly and can be a problem for any approved translation service. For example, within common law jurisdictions, such as the United Kingdom and the United States, the notion of equity is fundamental, but in civil law states, such as France and Spain, there is no such concept.

So what should the interpreter do in these situations? A common tactic is to leave "non-translatable" terms in the source language and then explain their meaning and context in the translator's note. All this is good, but what if the document is full of these concepts? You might end up with a translation that contains more notes than translators than the actual text, so that it takes no less than how long this translator takes.

\section{How do legal translators make sure they are ready to overcome these kinds of obstacles?}

Well, the main factor is experience. Legal translators typically require at least two years of experience under their leadership in dealing with these types of challenges to enable them to address them effectively. Legal translators also need to develop a very detailed understanding not only of their original legal system, but also of the legal systems from which all the documents they work on originate. This is why former lawyers often make some of the best legal translators.

Another effective weapon in the arsenal of the legal translator is research. Regardless of the translator's experience, the law is so broad, if not exhaustive, that there are likely terms or concepts that they are not familiar with after many years of experience. Adequate research is a key factor in ensuring that the source material is fully understood - a necessary introduction to be able to properly translate it into another language. What is clear is that legal translation can be one of the most difficult areas where a translator can specialize. As a result, when looking for a legal interpreter, he will do nothing better to ensure accuracy and clarity.

\section{Language barriers and victims}

For international victims, and perhaps some local victims, other important challenges to access services include cultural and language barriers. Victims may not learn about available services if information about these services is not provided in their mother tongue. In addition, some victims may be illiterate in their mother tongue. While most providers use an interpreter / interpreter to help communicate, having a third party can make it difficult for the provider (often the case manager) to develop a trust relationship with the victim.

Cultural differences can also interfere with the ability to provide or receive services and lead to culturally inappropriate services, insensitive responses, and / or misinterpretations of behavior or procedures. For example, victims who do not want to look directly at the person they are talking to may be misinterpreted by service providers as an indication that someone is hiding something or not telling the truth rather than understanding it as a sign of respect, as in some cultures. Basic logistical barriers, including lack of community knowledge, transportation or childcare, can prevent victims from accessing available services. ${ }^{2-5}$

Fugitive studies provide useful insights into why these young people do not use or stop using available services and programs. ${ }^{6,7}$ Reported barriers included restrictive rules in shelters; concerns about confidentiality, including concerns about reporting child protection services; lack of age-appropriate treatment groups; lack of culturally appropriate services; inability to build trust with staff owing to high turnover; Emotional, financial and other support that will help these victims leave the streets and exploit. ${ }^{8,9}$ With the exception of the latter, the barriers described here resemble the concerns expressed by international trafficking victims during individual interviews conducted as part of a larger assessment of comprehensive services for victims of trafficking. ${ }^{10}$

Some services may have potential legal consequences for victims. As with adult victims of domestic violence, the legal consequences of introducing them to drug addiction or mental health disorder can be profound for illegal immigrants in this country. A victim of international trafficking may fear that the problem may be documented and adversely affect a future immigration hearing or a possible detention case. ${ }^{10}$

With minors (but also with many adults), one of the biggest barriers is to persuade the victim to commit to drug abuse and / or mental health treatment. Research suggests that most adolescents do not introduce themselves to treat drug use voluntarily and therefore have low motivation for treatment; they are assigned either services or entry as a result of family pressure. ${ }^{11-21}$ Studies also document higher attrition rates in adolescent programs compared to adult programs. ${ }^{22-35}$

Research and program officials identify demographics (younger age, ethnic minority status, female sex, pregnant and parenting), severity of drug use, mental health symptoms, motivated readiness / treatment as major predictors of dropout. ${ }^{36-41}$

\section{Translation and non-native victims' rights}

To ensure that all victims of crime are treated equally, without 
discrimination, in mind Respect and ensure equal access to justice and rights for all victims of crime in addition to their active participation in criminal proceedings, they must understand and be so understood in any interaction they have with the criminal justice system. The right of interpretation and translation are among the main rights the victims. When contacting victims, the authorities must consider whether the victims speak or understands the language of victims. In order to gain access to their rights in criminal proceedings, it is important that victims can do so understand and understand the interactions that they have with the authorities within the Criminal Justice System. ${ }^{42-50}$

As an example of the case, we consider USA. The United States is a country of immigrants. From the Mayflower to the Irish potato famine to the Brasero program, the United States has seen an upsurge in its flow of individuals seeking new opportunities. According to the Pew Research Center, the number of foreign-born individuals in the United States has more than quadrupled since 1965, and is expected to reach 78 million by 2065.2. The rise, mostly fueled by Hispanic and Asian immigration, means that by 2044 the United States will become a "majority minority" nation, and no ethnic or ethnic group will dominate the United States in terms of population. This influx of people born abroad has resulted in more than 60 million people, or 21 percent of the US population, speaking a language other than English at home (4). Many, but not all, are considered "limited in English," that is, individuals who speak English are less than "very good". 5 Although most individuals with limited English proficiency are immigrants, about 19 percent (4.7 million) were born in the United States; most are immigrant children.6 Groups such as Puerto Ricans often move to the US mainland with skills. Limited in English.

States and cities with large immigrant communities and Puerto Rico have large populations with limited English proficiency; 44 per cent of California residents speak a language other than English at home, while in New York City 49 per cent speak. How can so many individuals access government-funded programs if they cannot communicate effectively in English? Under federal law, a person must have a meaningful language in federally funded programs if that person speaks a language other than English and has limited ability to read, write, speak or understand English.8 When the federal-funded program does not provide access to a person Limited proficiency in English, this program distinguishes based on national origin.

Access rights to language are essential in a person's life. Without access to a known language, anyone can inadvertently waive the right to something as fundamental as freedom - imagine that you read Miranda's rights in a language you don't understand and that your answer was used against you. The legal obligation to access language stems from the Sixth Civil Rights Act of 1964, which is further clarified by executive orders, guidelines of federal agencies, and courts. ${ }^{51-53}$

Assistance in the treatment of pain usually means translation and translation services. Interpretation is the act of listening to something in one language (the source language) and translating it orally into another language (the target language). Translation is the translation of written text from the source language into equivalent written text in the target language. Recipients need to ascertain whether interpreters and interpreters are properly trained and qualified.

The common misconception is that interpreters need certification. The certification requirement tends to exist in specific high-risk situations with a critical need for accuracy, such as courts and hospitals. In most cases, proficiency in interpretation skill and the ability to accurately communicate information in English and other language are sufficient.

However, be aware that "competence requires more than just bilingual identification. For example, some bilingual staff and community volunteers may be able to communicate effectively in a different language when communicating information directly in that language, but are not eligible for translation in and out of English. The interpreter shall have knowledge in both languages of any specialized terminology or concepts specific to the entity 's programs or activities.

The interpreter shall understand and follow the rules of confidentiality and integrity, without deviating from the role of the interpreter to provide advice or service in another capacity. Interpretation must take place in a timely manner: "At a time and place to avoid actual denial of service, benefit, or right to Issue or impose an undue burden on or delay in rights, benefits or services important to [limited English proficiency]".

\section{Conclusion}

As our communities and our client base continue to diversify, lawyers, especially those who work with underserved communities, must improve their ability to serve individuals with limited English proficiency. All legal professionals must learn to work effectively with interpreters, where they can be a powerful tool in case preparation and in breaking down barriers with clients with limited English proficiency. An effective interpreter will allow the lawyer and client to be more thorough and in-depth conversation on important issues in the case. History has shown us that despite government policies and racist rhetoric, the United States is a melting pot of cultures that will continue to evolve over time. The function of the legal community is to ensure access to justice for our population, whatever its composition.

\section{Acknowledgments}

None.

\section{Conflicts of interest}

The author declares there are no conflicts of interest.

\section{References}

1. Aiko J. The face of human trafficking. Hastings Women's Law Journal. 2002;13(1):31-52.

2. Clawson HJ, Dutch N. Addressing the needs of victims of human trafficking: Challenges, barriers, and promising practices. 2008.

3. Clawson H, Dutch N, Cummings M. Law enforcement response to human trafficking and the implications for victims: Current practices and lessons learned. 2006.

4. Clawson H, Layne M, Small K. Estimating human trafficking into the United States: Development of a methodology. 2006.

5. Clawson H, Small K, Go E, et al. Needs assessment for service providers and trafficking victims. 2004.

6. Bird Y. The challenges posed by insufficient collaboration and communication in the pro-active fight against trafficking of women: a victim centered approach to anti-trafficking work. Lyon: Interpol. 1999.

7. Najavits LM, Gallop RJ, Weiss RD. Seeking safety therapy for adolescent girls with PTSD and substance use disorder: A randomized controlled trial. J Behav Health Serv Res. 2006;33(4):453-463. 
8. Aviles A, Helfrich C. Life skill service needs: Perspectives of homeless youth. Journal of Youth and Adolescence. 2004;33(4):331-337.

9. Dalton MM, Pakenham KI. Adjustment of homeless adolescents to a crisis shelter: Application of a stress and coping model. Journal of Youth and Adolescence. 2002;31(1):79-89.

10. Caliber Associates. Evaluation of comprehensive service for victims of trafficking: Key findings and lessons learned. Final report submitted to the National Institute of Justice, U.S. Department of Justice. 2007.

11. Albanese J, Donnelly J, Kelegian T. Cases of human trafficking in the United States: A content analysis of a calendar year in 18 cities. International Journal of Comparative Criminology. 2004;4:96-111.

12. Allen D. Young male prostitutes: A psychosocial study. Archives of Sexual Behavior. 1980;9(5):399-426.

13. Alternatives for Girls. Tapestry 2006 annual report of alternatives for girls. 2006.

14. Amaro H, Blake SM, Schwartz PM, et al. Developing theory-based substance abuse prevention programs for adolescent girls. Journal of Early Adolescence. 2001;21(3):256-293.

15. Aronowitz AA. Smuggling and trafficking in human beings: The phenomenon, the markets that drive it and the organizations that promote it. European Journal on Criminal Policy and Research. 2001;9(2):163-195.

16. Austin AM, Macgowan MJ, Wagner EF. Effective family-based interventions for adolescents with substance use problems: A systematic review. Research on Social Work Practice. 2005;15(2):67-83.

17. Bagley C, Young L. Juvenile prostitution and child sexual abuse: A controlled study. Canadian Journal of Community Mental Health. 1987;6(1):5-26.

18. Bales K. Slavery and the human right to evil. Journal of Human Rights. 2010;3(1):53-63.

19. Bales K, Lize S. Trafficking in persons in the United States. 2005.

20. Bell RE. Sex trafficking: A financial crime perspective. Journal of Financial Crime. 2001;9(2):166-178.

21. Bennett LW, Stoops C, Call C, et al. Program completion and re-arrest in a batterer intervention system. Research on Social Work Practice. 2007; 17(1):42-54.

22. Brady KT, Dansky BS, Back SE, et al. Exposure therapy in the treatment of PTSD among cocaine-dependent individuals: Preliminary findings. $J$ Subst Abuse Treat. 2001;21(1):47-54.

23. Brannigan R, Schackman BR, Falco M, et al. The quality of highly regarded adolescent substance abuse treatment programs: Results of an in-depth national survey. Arch Pediatr Adolesc Med. 2004;158(9):904909.

24. Braun J. Collaborations: The key to combating human trafficking. The Police Chief. 2002;70(12).

25. Bureau of Justice Statistics. Law enforcement management and administrative statistics: Local police departments 2003. 2006.

26. Bureau of Labor Statistics. Youth employment in the United States. 2001.

27. Carmen EH, Crane W, Rieker PP, et al. Massachusetts task force report on the seclusion and restraint of persons with histories of physical and sexual abuse. Boston, MA: Massachusetts Department of Mental Health. 1996.

28. Carter V. Providing services to African American prostituted women. Journal of Trauma Practice. 2004;2(3-4):213-222.
29. Cauce AM, Morgan CJ, Wagner V, et al. Effectiveness of intensive case management for homeless adolescents: Results of a 3-month follow-up. Journal of Emotional and Behavioral Disorders. 1994;2(4):219-227.

30. Claudine O Leary, Olivia Howard. The prostitution of women and girls in metropolitan Chicago: A preliminary prevalence report. 2001.

31. Child Labor Coalition. Children in the fields: An American problem. 2007.

32. Child Labor Coalition. Children in the fields: The inequitable treatment of child farmworkers. 2007.

33. Child Labor Coalition. Youth peddling crews: Sweatshops of the streets. 2007.

34. Children of the Night. Rescuing America's children from prostitution. 2006.

35. Commercial Sexual Exploitation Resource Institute. Statement of philosophy. Minneapolis. 1998.

36. John Delamater. Sex for sale: Prostitution, pornography, and the sex industry. Contemporary Sociology: A Journal of Reviews. 2010;39(5):618-619.

37. Crowley TJ, Riggs PD. Adolescent substance use disorder with conduct disorder and comorbid conditions. NIDA Research Monographs. 1995;156:49-111.

38. Dabby F. Trafficking considerations and recommendations for domestic violence advocates. 2004

39. Dasinger LK, Shane PA, Martinovich Z. Assessing the effectiveness of community-based substance abuse treatment for adolescents. $J$ Psychoactive Drugs. 2004;36(1):27-33.

40. De Jong JTVM, Komproe IH, Van Ommeren M, et al. Lifetime events and posttraumatic stress disorder in four post conflict settings. JAMA. 2001;286(5):555-562.

41. Harlan S, Rodgers L, Slattery B. Male and female adolescent prostitution: Huckleberry House sexual minority youth services project. 1981.

42. Harris M, Fallot RD. Using trauma theory to design service systems. American Physiological Association. 2001.

43. Moxley Goldsmith T. Boys in the basement: Male victims of commercial sexual exploitation. American Prosecutors Research Institute. 2005;2(1):83-84.

44. Nadon S, Koverola C, Schludermann E. Antecedents to prostitution: Childhood Victimization. Journal of Interpersonal Violence. 1998;13(2):206-221.

45. Najavits LM, Weiss RD, Shaw SR, et al. Seeking safety: Outcome of a new cognitive-behavioral psychotherapy for women with posttraumatic stress disorder and substance dependence. J Trauma Stress. 1998;11(3):437-456.

46. Raphael J. Listening to Olivia: Violence, poverty, and prostitution. Boston, MA; Northeastern University Press. 2004.

47. Raphael J, Shapiro D. Sisters speak out: The lives and needs of prostituted women in Chicago, a research study. Chicago: Center for Impact Research. 2002.

48. Raymond J, Hughes D. Sex trafficking of women in the United States. 2001.

49. Richard AO. International trafficking in women to the United States: A contemporary manifestation of slavery and reorganized crime. The Center for the Study of Intelligence. 1999. 
50. Riley DB, Greif GL, Caplan DL, et al. Common themes and treatment approaches in working with families of runaway youths. American Journal of Family Therapy. 2004;32(2):139-153.

51. Rivard JC, McCorkle D, Duncan ME, et al. Implementing a trauma recovery framework for youths in residential treatment. Child and Adolescent Social Work Journal. 2004;21(5):529-550.
52. Szapocznik J, Perez Vidal A, Brickman AL, et al. Engaging adolescent drug abusers and their families in treatment: A strategic structural systems approach. J Consult Clin Psychol. 1988;56(4):552-557.

53. Teen Prostitution Prevention Project. Child sexual exploitation database report. 2006. 